
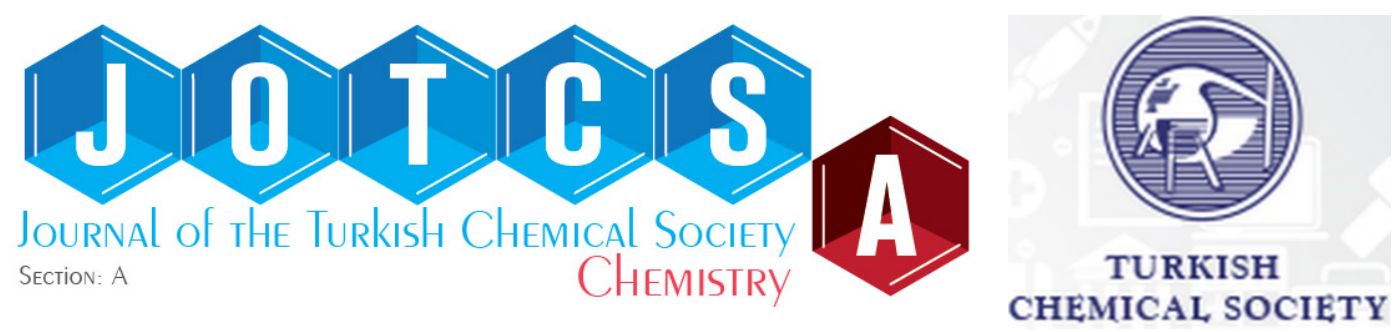

\title{
Nonlinear Fitting for Estimation of Adsorption Equilibrium, Kinetic and Thermodynamic Parameters of Methylene Blue onto Activated Carbon
}

\begin{abstract}
Ibrahim Y. Erwa1 ${ }^{1 D}$, Omer A. Ishag ${ }^{1 *}$ D, Omar A. Alrefaei ${ }^{1}$ D, Issa M. Hassan ${ }^{1}$
${ }^{1}$ International University of Africa, Faculty of Pure and Applied Sciences, Department of Applied and Industrial Chemistry (12223), Khartoum, Sudan.

Abstract: Adsorption equilibrium, kinetics, and thermodynamics of methylene blue dye (MB) from aqueous solutions onto activated carbon (AC) synthesized from pomegranate peel was conducted in controlled batch systems. The effects of initial MB concentration, AC particle size, contact time, and temperature on adsorption were evaluated. Under the optimized conditions (i.e., contact time $120 \mathrm{~min}$, $\mathrm{pH} \sim 5$, particle size $125 \mu \mathrm{m}$, dye concentration $20 \mathrm{mg} / \mathrm{L}$, temperature $333 \mathrm{~K}$, and $0.5 \mathrm{~g} \mathrm{AC} / 50 \mathrm{~mL} \mathrm{MB}$ solution), the removal percentages can achieve $\sim 98.28 \%$. The nonlinear method was conducted for estimating the equilibrium and kinetic parameters, where the equilibrium data were fitted to the Langmuir isotherm model. The Langmuir isotherm suggested a maximum monolayer adsorption capacity of $5.03 \mathrm{mg} / \mathrm{g}$ at $60^{\circ} \mathrm{C}$. The pseudo-second-order kinetic model provided the best fit to the experimental data compared with the pseudo-first-order. Kinetic studies showed that the adsorption equilibrium was rapidly established, with low activation energy entailed for adsorption (Ea; $15.60 \mathrm{~kJ} / \mathrm{mol}$ ). Thermodynamic parameters showed that the adsorption was spontaneous $\left(-\Delta \mathrm{G}^{\circ}\right.$ and $\left.+\Delta \mathrm{S}^{\circ}\right)$, endothermic $\left(+\Delta \mathrm{H}^{\circ}\right)$, and favorable at ambient conditions.
\end{abstract}

Keywords: Methylene blue, adsorption isotherms, kinetics, thermodynamic parameters, nonlinear fitting.

Submitted: March 27, 2021. Accepted: November 30, 2021.

Cite this: Erwa I, Ishag O, Alrefaei O, Hassan I. Nonlinear Fitting for Estimation of Adsorption Equilibrium, Kinetic and Thermodynamic Parameters of Methylene Blue onto Activated Carbon. JOTCSA. 2022;9(1):67-84.

DOI: https://doi.org/10.18596/jotcsa.904311.

*Corresponding author. E-mail: adamomer4@gmail.com.

\section{INTRODUCTION}

Pollution of the aquatic environment resulting from the discharging of insufficiently treated industrial wastes containing relatively large quantities of some chemicals of industrial origin, such as dyes, phenols, coloring materials, pesticides, and fertilizers, into water sources is a growing environmental problem and a direct threat to the life of all living organisms (1). In addition to being a major factor causing a lack of healthy food, disease, and death, water pollution often leads to a persistent shortage of clean drinking water accessible around the world (2). About $75-80 \%$ of water pollution results from improperly treated industrial wastewater discharges, as waste from industries such as sugar, textiles, electroplating, and pesticides pollute the water to a large extent (3). Color is one of the most obvious water pollution indicators, and the release of colored effluents can pollute aquatic bodies. These pollutants come from synthetic dyes widely utilized in numerous industries, incorporating dyeing of textiles, paper, and plastics that consume $60 \%$, $10 \%$, and $10 \%$ of global pigment production, respectively (4). The textile industry alone uses about $1.0 \times 10^{4}$ different types of dyes (5). The world's annual production of dyes is over $7.0 \times 10^{5}$ tons $(6,7)$. It is estimated that $10-15 \%$ of the used dye is discarded in the effluent during the dyeing process (8). Wastewater contaminated with highly colored dyes requires appropriate treatment 
before release into the environment (9). It is difficult to remedy such wastewater by conventional wastewater treatment methods because the organic dye molecules resist aerobic digestion, and some are stable to light, heat, and oxidation processes. Moreover, some azo dyes and their analogs contain carcinogenic compounds, so treating liquid wastes containing these compounds is important to protect natural waters (4). On the other hand, the chemical treatment method requires large quantities of chemicals, and additional treatment should be taken into account for secondary protection from the reaction products, which increases the cost of the process (10). Therefore, research continues to develop an efficient and environmentally friendly new technology to treat harmful organic pollutants in industrial wastewater. Several methods have been developed, such as coagulation, membrane filtration, adsorption, catalyzed photolysis, aerobic and anaerobic decomposition, advanced oxidation, and ozone treatment to treat waste organic dyes (11-14). Adsorption is considered one of the best techniques used to remove dye from a solution due to its high efficiency, effectiveness, and low cost (15). In this regard, well-known adsorbents, such as activated carbon (16), biomass (17) zeolite, clay materials (18), and polymers (19), are used to remove the contaminating dyes. The adsorption is classified based on the adsorbate-adsorbent interaction and the heat associated with the process. The type and strength of the bonds between the adsorbent and the substrate provide a clear indication of the type of adsorption, beginning with weaker bonds such as van der Waals forces or so-called physical adsorption, and even strong bonds in the case of chemical adsorption, where chemical bonds are established between the substrate and the adsorbent surface (20). The adsorption capacity depends on the relationship between the adsorbent's surface area and the nature and size of the adsorbate. The adsorption process is accompanied by a change in the free energy $(\Delta G)$, as well as a decrease in the entropy $(\Delta S)$ due to the restriction of the particles that have adsorbed to the adsorbent surface, and in general, the adsorption process is mostly exothermic, and this does not prevent some types of endothermic adsorption from occurring. Activated carbon is a porous carbon material increasingly used due to its exceptional properties in desalination, wastewater treatment plants, and air purification (21). The advantages of activated carbon adsorbents are reasonably priced wastewater treatment, clear process design, fast process application, corrosive resistance, high adsorption ability in gas and liquid purification, and their use as supporting catalysts (22). In general, activated carbon is produced from biomass and agricultural waste in two major steps: pyrolysis or carbonization and activation (23). Many low-cost waste materials of plant origin have been studied to produce activated carbon because they contain minimum organic matter, long shelf life, and a solid structure that preserves their properties under varying operating conditions. For this purpose, agricultural by-products were used, such as sugarcane bagasse, peanut husks, rice straw, soybean husk, walnut husks, and pecan husks (24). Methylene blue (MB) is a basic or cationic dye, also recognized as methylthioninium chloride and other common names; its IUPAC name is $(3,7-$ bis(dimethylamino)-phenothiazin-5-ium chloride). Methylene blue is a dark green crystalline powder. It has a slight odor; it is very soluble in water $43.60 \mathrm{~g} / \mathrm{L}$ at $25^{\circ} \mathrm{C}$, and it is commonly used as a staining agent in research labs and textile factories and is often used as an adrenaline aid in the ablation process $(25,26)$. It has a chemical formula $\left(\mathrm{C}_{16} \mathrm{H}_{18} \mathrm{~N}_{3} \mathrm{SCl}\right)$, molecular mass (319.85 $\mathrm{g} / \mathrm{mol}$ ); it absorbs light strongly at wavelengths of 589 and $664 \mathrm{~nm}$ (15). MB molecules' highly toxic nature makes them a possible threat to human health and the natural environment (27). Direct contact with MB induces dermatitis and permanent damage to the eyes, and MB-rich water intake results in diarrhea, vomiting, nausea, gastritis, delirium, and heavy sweating (28). This study aims to remove methylene blue (MB) from synthetic wastewater by a batch adsorption process using low-cost activated carbon (prepared from pomegranate peel waste) as an adsorbent and to study the process equilibrium, kinetics, and thermodynamic using the nonlinear regression analysis.

\section{EXPERIMENTAL SECTION}

\section{Chemicals and Equipment}

All chemicals used in this study were of analytical grade, as follows: MB (C.I. 52015, Merck), sodium hydroxide, and hydrochloric acid (NICE, India). A stock aqueous solution of $\mathrm{MB}(1000 \mathrm{mg} / \mathrm{L})$ was prepared. A water bath (Model 1008, G.F.L.) was used for all the adsorption experiments. For the estimation of MB concentrations, a UV/Visible spectrophotometer (Model CE7200, Aquarius) was used. A muffle furnace (Carbolite) and drying oven (SLW 15 POL-EKO-APARATURA) were used to prepare activated charcoal.

\section{Carbonization of Pomegranate Peel}

About $100 \mathrm{~g}$ of well-cleaned, dried, and grounded pomegranate peel was blended with $100 \mathrm{~mL}$ of 0.1 $\mathrm{M} \mathrm{NaOH}$ solution in a closed crucible and carbonized in the muffle furnace $\left(650^{\circ} \mathrm{C}\right)$ for $1 \mathrm{~h}$ in the absence of oxygen. The crucible was then removed from the furnace and left to cool at room temperature. The prepared charcoal was washed with distilled water, to remove the excess $\mathrm{NaOH}$, and with $0.1 \mathrm{M} \mathrm{HCl}$ solution to remove residues of activating agent which clog the pores, finally 
washed with deionized water to remove any surface impurities. The cleaned charcoal sample was dried at $105^{\circ} \mathrm{C}$ and subsequently activated at $250{ }^{\circ} \mathrm{C}$ for $24 \mathrm{~h}$ in an oven, then allowed to cool in the desiccator. The dried sample was powdered and sieved using different micrometers aperture sieve sizes $(29,30)$.

\section{Determination of Bulk Density of the Adsorbent}

A pre-weighed dry density bottle was filled with the prepared activated carbon (AC), the spaces between the carbon particles were removed by lightly striking the bottle, then the density bottle and its contents were accurately weighted. The bulk density was calculated using Equation 1:

$$
\text { Bulk density }=\frac{\text { weight of charcoal }}{\text { volume }}
$$

\section{Determination of Moisture Content of the Adsorbent}

About $5 \mathrm{~g}$ of the AC samples were balanced in a dry and weighed porcelain crucible. Crucible was heated $\left(105^{\circ} \mathrm{C}\right)$ for $2 \mathrm{~h}$ in an electric oven. The crucible was cooled in a desiccators then reweighed. The procedure was repeated until achieving a constant weight. The adsorbent moisture content was calculated utilizing Equation 2:

$$
\text { Moisture content }(\%)=\frac{w_{2}-w_{3}}{w_{2}-W_{1}} \times 100
$$

Where: $w_{1}$ is empty crucible weight; $w_{2}$ is crucible and sample weight; $w_{3}$ is crucible and sample weight after heating.

\section{Determination of Ash Content of the Adsorbent}

About $5 \mathrm{~g}$ of the prepared AC was weighed into a dry and weighed crucible and transferred to the muffle furnace at $500{ }^{\circ} \mathrm{C}$ for $2 \mathrm{~h}$ (30), where ash content was calculated utilizing Equation 3:

$$
\text { Ash content }(\%)=\frac{\text { weight of ash }}{\text { sample weight }} \times 100
$$

\section{Batch Adsorption Study}

Batch adsorption experiments were conducted in an isothermal shaker at an agitation speed of 250 rpm utilizing a sequences of $100 \mathrm{~mL}$ Erlenmeyer flasks. In all sets of experiments, $50 \mathrm{~mL}$ of $\mathrm{MB}$ solutions (natural $\mathrm{pH}=5.01$ without any further adjustment) was added to $0.5 \mathrm{~g}$ of $\mathrm{AC}$. The influence of various adsorption parameters, initial concentrations $(10,20,30,40,50,60,70,90$, $110,130$, and $150 \mathrm{mg} / \mathrm{L})$, contact time ( $1-120$ $\mathrm{min})$, adsorbent particle size (50,63, 125 and 250 microns $)$ and temperature $\left(20-60{ }^{\circ} \mathrm{C}\right)$ was investigated by varying the parameter under investigation, while all other experimental parameters have remained constant. After equilibrium, the solutions were filtered, and the dye's concentration in the filtrates was determined by measuring the absorbance at $664 \mathrm{~nm}$ using a double beam UV-Vis spectrophotometer. The adsorption capacity $\left(\mathrm{q}_{\mathrm{e}}\right)$ and $\mathrm{MB}$ removal percentage $(R \%)$ was calculated using the following expressions:

$$
\begin{aligned}
q_{e} & =\frac{\left(C_{i}-C_{e}\right) V}{m} \\
R(\%) & =\frac{C_{i}-C_{e}}{C_{i}} \times 100
\end{aligned}
$$

Where $q_{e}$ is the quantity of $M B$ adsorbed per unit mass of adsorbent $(\mathrm{mg} / \mathrm{g}), C_{i}$ is the initial concentration of $M B(\mathrm{mg} / \mathrm{L}), C_{e}$ is the equilibrium concentration of $M B(\mathrm{mg} / \mathrm{L}), V$ is the $M B$ solution volume $(\mathrm{L})$, and $\mathrm{m}$ is the adsorbent mass $(\mathrm{g})$. All measurements were repeated three times, and the mean values were taken.

\section{Statistical Analysis}

The Origin software version 8.5 was used to compute the kinetic and isotherm models' parameters precisely in batch experiments. The coefficient of determination $\left(R^{2}\right)$ of the nonlinear optimization method was calculated utilizing Equation 6. For the assessment of the fit of the equations to the experimental data of the adsorption process a nonlinear $\left(R^{2}\right)$, chi-square $\left(X^{2}\right)$, and the adjusted coefficient of determination $\left(R^{2}{ }_{\text {adj }}\right.$ ) (Equations $6-8$ ) values were determined.

$$
\begin{gathered}
R^{2}=1-\frac{\sum\left(q_{e, \exp }-q_{e, \text { cal }}\right)^{2}}{\sum\left(q_{e, \exp }-q_{e, \text { mean }}\right)^{2}} \\
\mathrm{X}^{2}=\frac{\sum\left(q_{e, \exp }-q_{e, \text { cal }}\right)^{2}}{q_{e, \text { cal }}} \\
R_{a d j}^{2}=1-\left(1-R^{2}\right)\left(\frac{n_{p}-1}{n_{p}-p-1}\right)
\end{gathered}
$$

Where $q_{e, \exp }(\mathrm{mg} / \mathrm{g})$ is the amount of MB uptake at equilibrium obtained from Equation $4 ; \mathrm{q}_{\mathrm{e}, \mathrm{cal}}(\mathrm{mg} / \mathrm{g})$ is the amount of MB adsorbed computed from the model using the Origin software; $\mathrm{q}_{e, \text { mean }}(\mathrm{mg} / \mathrm{g})$ is the average of $q_{e, e x p}$ values; $n_{p}$ is the number of experiments carried out, $p$ is the number of parameters of the fitted model.

\section{Adsorption Isotherm}

Two well-known equilibrium isotherm models (Langmuir and Freundlich) were used to describe experimental adsorption data. According to Langmuir, adsorption occurs over a homogenous 
surface through monolayer adsorption, where all the adsorption positions are duplicate and energetically equivalent. The nonlinear formula of the Langmuir model shown in Equation 9, and one linear formula of the equation is represented in Equation 10:

$$
\begin{gathered}
q_{e}=\frac{Q_{\text {max }} K_{L} C_{e}}{1+K_{L} C_{e}} \\
\frac{C_{e}}{q_{e}}=\frac{1}{Q_{\text {max }} K_{L}}+\frac{C_{e}}{Q_{\text {max }}}
\end{gathered}
$$

Where: $\mathrm{q}_{\mathrm{e}}$ and $\mathrm{Q}_{\max }$ are equilibrium adsorption capacity $(\mathrm{mg} / \mathrm{g})$ and maximum adsorption capacity $(\mathrm{mg} / \mathrm{g})$ of $\mathrm{MB}$ on $\mathrm{AC}$, respectively; $\mathrm{C}_{e}$ is the equilibrium concentration $(\mathrm{mg} / \mathrm{L}) ; \mathrm{K}_{\mathrm{L}}$ is the Langmuir constant (L/mg).

The nonlinear and linear forms of the Freundlich model are described in Equation 11 and Equation 12 , respectively.

$$
\begin{gathered}
q_{e}=K_{F} C_{e}^{n} \\
\log q_{e}=\log K_{F}+n \log C_{e}
\end{gathered}
$$

Where: $\mathrm{K}_{\mathrm{F}}$ and $\mathrm{n}$ are Freundlich constants (31).

\section{Adsorption Kinetics}

Lagergren's nonlinear pseudo-first-order equation (PFO) (Equation 13) and Blanchard et al. nonlinear pseudo-second-order (PSO) (Equation 14) kinetic models were adopted to analyze the experimental results in order to fully understand the adsorption process of $M B$ on the surface of the prepared $A C$ (32).

$$
\begin{aligned}
q_{t} & =q_{e}\left(1-e^{-k_{1} t}\right) \\
q_{t} & =\frac{q_{e}^{2} k_{2} t}{1+k_{2} q_{e} t}
\end{aligned}
$$

\section{Adsorption Thermodynamics}

An essential element of determining adsorption type (physisorption or chemisorption) is conducting thermodynamic analysis. The functions (thermodynamic) for the adsorption of $M B$ by $A C$ derived from pomegranate peel (33) can be determined utilizing the equations:

$$
\Delta G^{0}=-R T \ln K_{c}
$$

Where $\Delta \mathrm{G}^{\circ}$ is the Gibbs energy change, $\mathrm{R}$ is the universal gas constant $(8.314 \mathrm{~J} / \mathrm{mol} . \mathrm{K}), \mathrm{T}$ is the absolute temperature in $\mathrm{K}$, and $\mathrm{K}_{\mathrm{C}}$ (dimensionless) is the equilibrium constant. The equilibrium constant was derived from the value of the best-fit nonlinear isotherm model. $\mathrm{K}_{\mathrm{C}}$ can simply be acquired as a dimensionless constant depending on the appropriate equilibrium unit isotherm constant. Using the Gibbs equation, the relationship between Gibbs energy changes $\left(\Delta \mathrm{G}^{\circ}\right)$, enthalpy change $\left(\Delta \mathrm{H}^{\circ}\right)$ and entropy changes $\left(\Delta \mathrm{S}^{\circ}\right)$ of adsorption can be defined as follows:

$$
\Delta G^{0}=\Delta H^{0}-T \Delta S^{0}
$$

By substituting Equation 15 into Equation 16, the famous Van't Hoff correlation is derived (Equation 17):

$$
\ln K_{c}=\frac{-\Delta H^{0}}{R} \times \frac{1}{T}+\frac{\Delta S^{0}}{R}
$$

$\Delta \mathrm{G}^{\circ}$ is calculated directly from Equation 15 , while $\Delta H^{\circ}$ and $\Delta S^{\circ}$ are calculated from the slope and intercept of a plot of InK $\mathrm{K}_{\mathrm{c}}$ against $1 / \mathrm{T}$ (Equation 17).

\section{RESULTS AND DISCUSSION}

\section{Physical Properties of the Adsorbent}

Some properties (bulk density, moisture, and ash content) of the prepared AC were presented in Table 1 . These results were consistent with the findings of Dekhyl and Mohamed (29) and Ali and Fatthee (34). Often activated carbon is condensed to obtain a larger storage capacity for the same volume (30), but a density of $0.40 \mathrm{~g} / \mathrm{cm}^{3}$ was obtained for the prepared AC. Some reports relate the bulk density to the rate of adsorption (35). Bulk density may probably have the same effect on the adsorbent used in this study. The value of moisture content was relatively low; according to Moyo, Chikazaza (35), moisture content does not affect adsorption capacity. As shown in Table 1, the ash content was low, indicating that a significant portion of the inorganic materials and ash components were removed during the washing step by $\mathrm{NaOH}$ and $\mathrm{HCl}$ solutions (36). The low ash level increases the activity of the carbon.

Table 1: The physical properties of the prepared charcoal.

\begin{tabular}{ccc}
\hline Ash content (\%) & Moisture content (\%) & Density $\left(\mathbf{g} / \mathbf{c m}^{\mathbf{3}}\right)$ \\
\hline $5.65 \pm 0.04$ & $8.05 \pm 0.18$ & $0.40 \pm 0.01$ \\
\hline *Values are mean \pm SD & &
\end{tabular}

\section{Standard Calibration Curve for MB}

Figure 1 shows the standard calibration curve for MB. The wavelength scanned for the standard solutions between 450 - $900 \mathrm{~nm}$ showed absorption maxima, $\lambda_{\max }$ at $664 \mathrm{~nm}$. The Beer's law was verified from the calibration curve by 
plotting graphs between concentration against absorbance, whereby a leaner curve passed through the origin ( $y=0.19816 x$ ) was obtained.
Beer's law was obeyed in the concentration range $1.00-8.00 \mathrm{mg} / \mathrm{L}$.

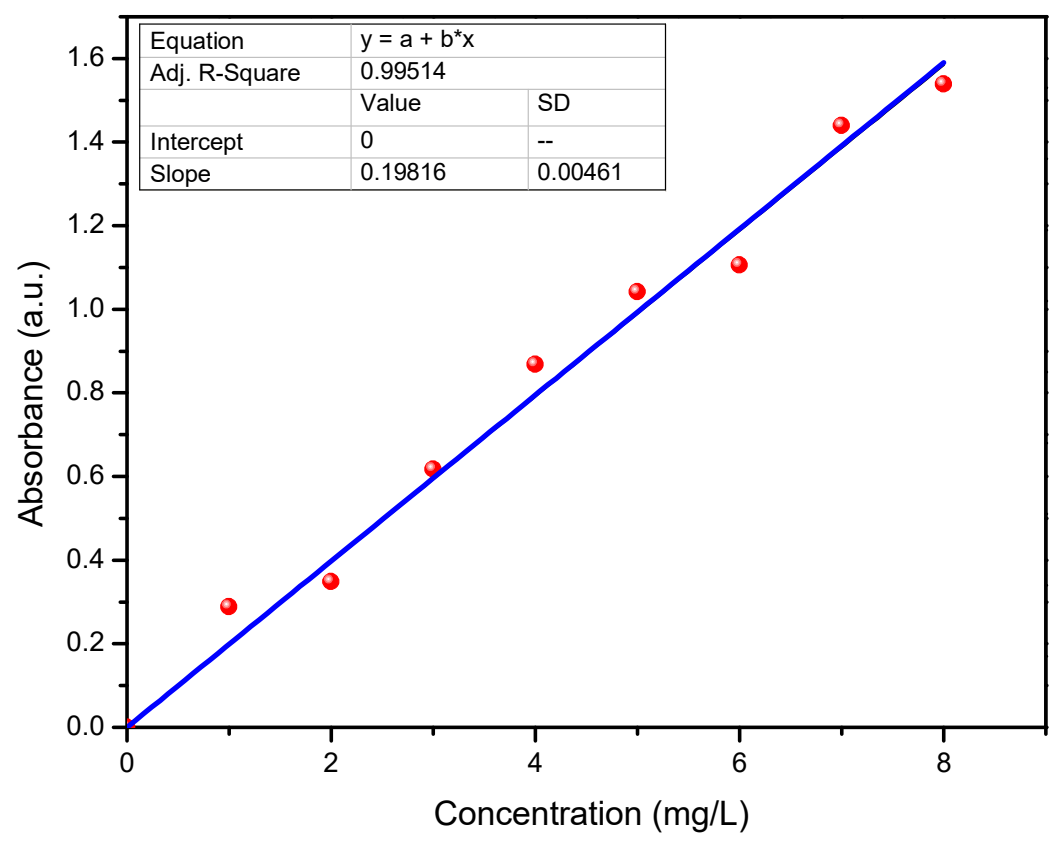

Figure 1: Standard calibration curve for methylene blue.

\section{Effect of Initial Solution Concentration}

It is obvious that the percentage of removed adsorbate (MB) from aqueous solution by $A C$ derived from pomegranate peel depends on the initial concentration of the dye solution, as shown in Figure 2. The removal\% is high (94.45 $85.87 \%$ ) at low initial concentrations of $\mathrm{MB}$ solution (10 - $50 \mathrm{mg} / \mathrm{L})$. However, the removal percentage decreased gradually from $61.74 \%$ to $6.66 \%$ at higher dye concentrations, corresponding to the concentration range of $60-150 \mathrm{mg} / \mathrm{L}$. At low concentrations, the dye is adsorbed by the empty active adsorption sites on the adsorbent's surface, while at higher concentrations, the adsorption rate decreases due to the saturation of adsorption sites. The accumulation of MB dye molecules on the surface of the activated charcoal may be attributed to the lack of sufficient surface area to accommodate much more dye molecules available in the solution $(37,38)$. However, utilization of removal\% to express adsorption capacity should be utilized cautiously as it is very approximate and can cause ambiguous assumptions about relative adsorption performance (39). So utilization removal\% in the study of adsorption equilibria can lead to inaccurate observations and conclusions. The substrate's quantity adsorbed onto an adsorbent depended on the equilibrium concentrations of dye's $\left(\mathrm{q}_{\mathrm{e}}\right)$, the $\mathrm{pH}$ of solution, and temperature. Thus, adsorption isotherm should be assumed as a relationship between dye $\left(\mathrm{C}_{e}\right)$ equilibrium concentration and the equilibrium adsorbed amounts per unit mass of adsorbent $\left(\mathrm{q}_{\mathrm{e}}\right)$ at carefully controlled environmental parameters of the system, namely the $\mathrm{pH}$ of the solution and temperature. The results demonstrate that adsorption performance of $\mathrm{MB}$ on $\mathrm{AC}$ derived from pomegranate peel depends on the equilibrium concentration of the dye solution, as in Figure 5. The maximum adsorption performance of $\mathrm{MB}\left(\mathrm{q}_{\mathrm{e}}=5.03 \mathrm{mg} / \mathrm{g}\right)$ at $60{ }^{\circ} \mathrm{C}$ was observed in the $\mathrm{MB}$ dye initial concentration of $90 \mathrm{mg} / \mathrm{L}$, where $C_{e}$ is $40.00 \mathrm{mg} / \mathrm{L}$. At $25{ }^{\circ} \mathrm{C}$, the adsorption uptakes of $\mathrm{MB}$ at equilibrium increased from 1.84 to $4.32 \mathrm{mg} / \mathrm{g}$ as the equilibrium dye concentration was increased from 1.62 to $46.82 \mathrm{mg} / \mathrm{L}$. In contrast, the saturation of the active positions on the surface occurs in this case (40), the ratio of MB molecules in solution to unoccupied active positions of adsorbent becomes large, and subsequently, the quantity of adsorbate adsorbed at equilibrium ( $q_{e}$; $\mathrm{mg} / \mathrm{g}$ ) becomes independent of $\mathrm{MB}$ concentration $(41,42)$. 


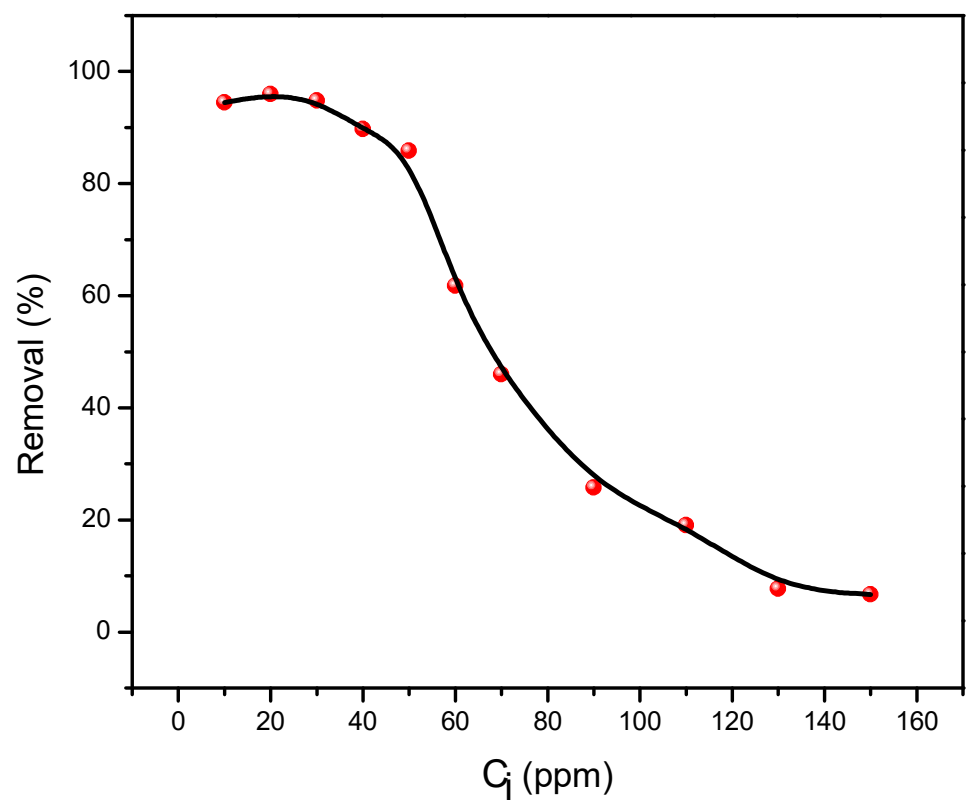

Figure 2: The effect of initial concentration on adsorption of $\mathrm{MB}$ on activated charcoal at $30^{\circ} \mathrm{C}$

\section{Effect of Contact Time}

In order to study the effect of contact time on the MB uptake, $50 \mathrm{~mL}$ of $\mathrm{MB}$ solutions with an initial concentration of $20 \mathrm{mg} / \mathrm{L}$ was shaken with $0.5 \mathrm{~g}$ of $A C$ for different time periods ranging from 1 minute to 120 minutes at constant temperatures of $35^{\circ} \mathrm{C}$ and $60{ }^{\circ} \mathrm{C}$ separately, with a rotation speed of $120 \mathrm{rpm}$, and the solution $\mathrm{pH}$ was kept original without any $\mathrm{pH}$ adjustment. It is evident from Figure 6 that the adsorption capacity of MB increased with a contact time quickly at the beginning, and after that, the rate was gradually lowered, and finally, the curve becomes parallel to the time axis when the system attained equilibrium. Based on the result, suggestion adsorption occurs quickly at the initial stage on the adsorbent's external surface, followed by a slower internal diffusion process, which is perhaps the rate-determining step (32). Moreover, the rapid adsorption at the initial stage may also be because a large number of surface sites are available for adsorption, but after a lapse of time, the remaining surface positions are challenging to be occupied. It was found that the equilibrium state was reached after about 50 minutes with a removal\% of $>$ $96.5 \%$. This result agrees with that reported by many authors (43).

\section{Effect of Temperature}

The temperature of the solution is an essential factor that affects the absorption efficiency; Figure 3 exhibits the correlation between the solution temperature and the percentage of $\mathrm{MB}$ removal at temperatures of $20,30,40,50$, and $60^{\circ} \mathrm{C}$ when the initial dye concentration was $20 \mathrm{mg} / \mathrm{L}$, as shown, increasing solution temperature from 20 to $60{ }^{\circ} \mathrm{C}$ leads to an increase in the equilibrium adsorption capacity, this suggests that the adsorption process, in this case, is endothermic (44) as confirmed by the thermodynamic parameter values, determined later. This increase in adsorption capacity may suggest that increasing the kinetic energy of MB molecules with increasing temperature contributes to an increase in the adsorption rate on the adsorbent surface by increasing the number of molecules that obtain adequate energy to adsorb to the active positions on the surface. 


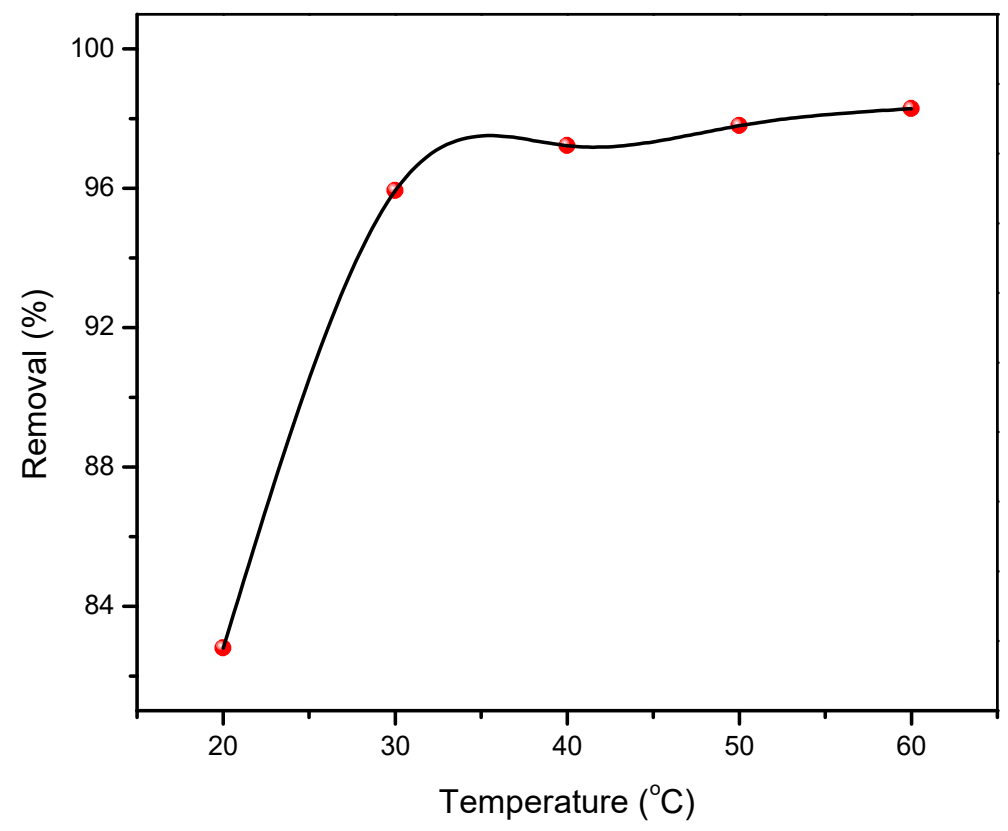

Figure 3: Effect of solution temperature on MB adsorption onto AC at constant other parameters.

\section{Effect of Particle Size}

The MB removal percentages of $250,125,63$, and 50 mesh particles at the contact time of $2 \mathrm{~h}$ were $87.51,95.94,87.64$, and $80.45 \%$, respectively (Figure 4). The effect of particle size on the adsorption process was studied using a fixed concentration of MB solutions (20 mg/L) and a constant weight $(0.5 \mathrm{~g})$ of the adsorbent material. It is evident from the obtained results that particle size influences the adsorption efficiency, and there is a direct relative association between particle size and surface area. The adsorption increases until it attains a maximum at a particle size of $125 \mu \mathrm{m}$, which has the highest available surface area for adsorption and an ideal number and size of pores; thus, the ratio of active sites to volume increases relatively, and then begins to decrease with the increase in particle size due to the decrease in surface area compared to volume, this observation is consistent with what was reported by Emad and Stephen (45).

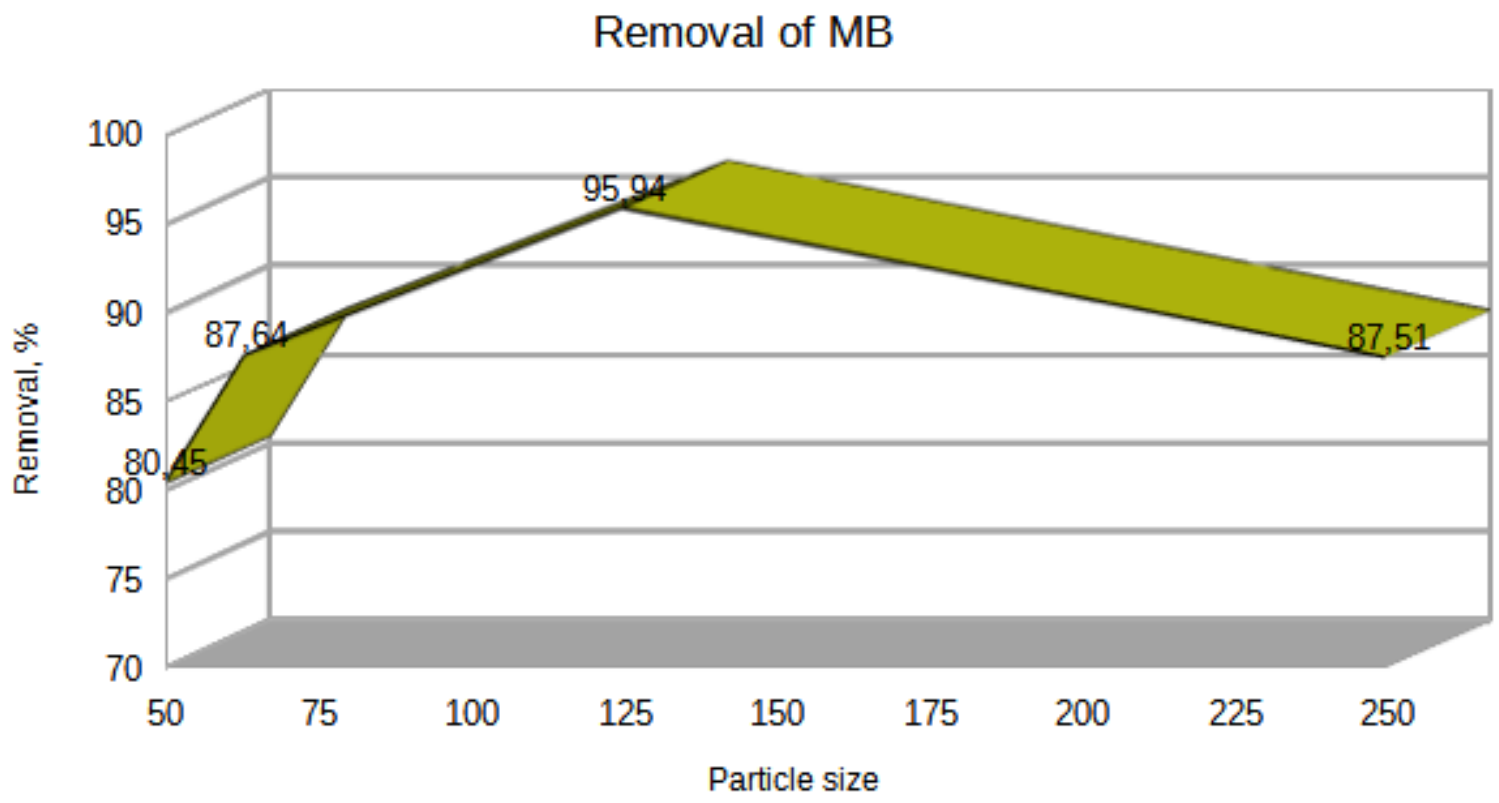

Figure 4: Effect of particle size of $A C$ on removal\% of $M B$. 


\section{Adsorption Isotherms}

Adsorption isotherm illustrates the variation of $\theta$ (the fractional coverage of the surface) with an equilibrium concentration of adsorbate $\left(\mathrm{C}_{e} ; \mathrm{mg} / \mathrm{L}\right)$ at a chosen temperature. $\theta$ can be expressed as the quantity of adsorbate adsorbed by adsorbent $\left(\mathrm{q}_{\mathrm{e}} ; \mathrm{mg} / \mathrm{g}\right)$. In the literature, the most used and studied isotherm equation is Langmuir equation. Several additional isotherm models are also well explored in the literature, for instance Freundlich isotherm, Sips isotherm, Liu isotherm, and RedlichPeterson isotherm (46). The adsorption capacity depends on the equilibrium concentration of the adsorbate, the $\mathrm{pH}$, and the solution's temperature. Therefore, the absorption system's environmental parameters must be carefully monitored at specified values throughout the experiment period (47). The adsorption models' parameters provide valuable information on the adsorbate-adsorbent interactions, surface properties, and adsorption mechanism. However, it is less valuable than kinetics and thermodynamics in clarifying the adsorption mechanism. The $\mathrm{q}_{\mathrm{e}}$ versus $\mathrm{C}_{\mathrm{e}}$ graph of the whole adsorption isotherm plays a significant role in determining the regions where the empirical data for the adsorption equilibrium is actually present (48). Vasanth Kumar and Sivanesan (49) have proposed that using the equilibrium data covering the entire isotherm is the best method to achieve the parameters in isotherm expressions. In this research, the nonlinear form of well-known equilibrium isotherm models (Langmuir (Equation 9) and Freundlich (Equation 11)) was conducted to elucidate the adsorptive behavior of $M B$ dye onto the $A C$ and to calculate the adsorption isotherms parameters to avoid the most common error in analyzing adsorption equilibrium data associated with the use of linear formulas of models. According to Langmuir, adsorption takes place over a homogenous surface through monolayer adsorption, where all the adsorption positions are duplicate and energetically equivalent. The nonlinear form of the Langmuir model is shown in Equation 9. Conversely, the Freundlich model is an experimental equation constructed on a heterogeneous surface. Its nonlinear form is described in Equation 11. Langmuir constant, $\mathrm{K}_{\mathrm{L}}$ $(\mathrm{L} / \mathrm{mg})$ is correlated to the association amongst adsorbents and adsorbates whereas Freundlich constants, $\mathrm{K}_{\mathrm{F}}((\mathrm{mg} / \mathrm{g}) /(\mathrm{mg} / \mathrm{L}) \mathrm{n})$ and $\mathrm{n}$, (dimensionless; $0<n<1$ ) are correlated to adsorption capacity and adsorption intensity, respectively (31). The Freundlich constant, n, which characterizes the adsorption strength, illustrates the intensity of adsorption's driving force or surface's heterogeneity (adsorption isotherm becomes linear when $n=1$, favorable when $n<1$, and unfavorable when $n>1$ ).

When studying the adsorption equilibrium using the Langmuir model, it is appropriate to compute the value of the separation factor $R_{L}$ (dimensionless), through which the basic properties of the Langmuir isotherm are expressed. The separation factor is defined in Equation 18 as follows:

$$
R_{L}=\frac{1}{1+K_{L} C_{0}}
$$

Where $R_{L}$ is a separation factor (dimensionless) of a solid-liquid adsorption system, $\mathrm{K}_{\mathrm{L}}$ is the equilibrium constant of Langmuir, and $C_{0}$ is the initial concentration of MB. The separation factor, $\mathrm{R}_{\mathrm{L}}$ was utilized to predict whether the adsorption system was favorable $\left(0<R_{L}<1\right)$, unfavorable $\left(R_{L}>1\right)$, linear $\left(R_{L}=1\right)$, or irreversible $\left(R_{L}=0\right)$ (31).

The adsorption isotherms (Langmuir and Freundlich) plots for the adsorption of MB onto AC obtained from pomegranate peel at different temperatures are shown in Figure 5 (a) and (b), respectively. It is evident that the experimental data are highly consistent with the adsorption equilibrium in the region expressed with the Langmuir model, which is described via saturation at high concentrations. This assumption is supported by the higher value of adjusted determination coefficients $\left(R_{\text {adj }}^{2}=0.97955\right)$ and lower chi-square values $\left(X^{2}=0.02766\right)$ of the Langmuir model compared to those of Freundlich model $\left(R^{2}{ }_{\text {adj }}=0.72963 ; X^{2}=0.36572\right)$. In addition, the exponent value, $\mathrm{n}=0.1667$ (a parameter of the Freundlich equation), was less than 1, reflecting favorable conditions for adsorption. Also, the values of separation factor $\left(R_{L}\right)$, calculated from Langmuir constant $\mathrm{K}_{\mathrm{L}}$, for different initial concentrations were lying in the range of $\left(0<R_{L}<\right.$ $1)$, indicates that the adsorption was favorable, as shown in Table 2. Therefore, mathematically, the Langmuir model is better than the Freundlich model to describe the adsorption isotherm of $M B$ dye on $A C$. , i.e., and the observed adsorption behavior was predominantly monolayer chemisorption. 


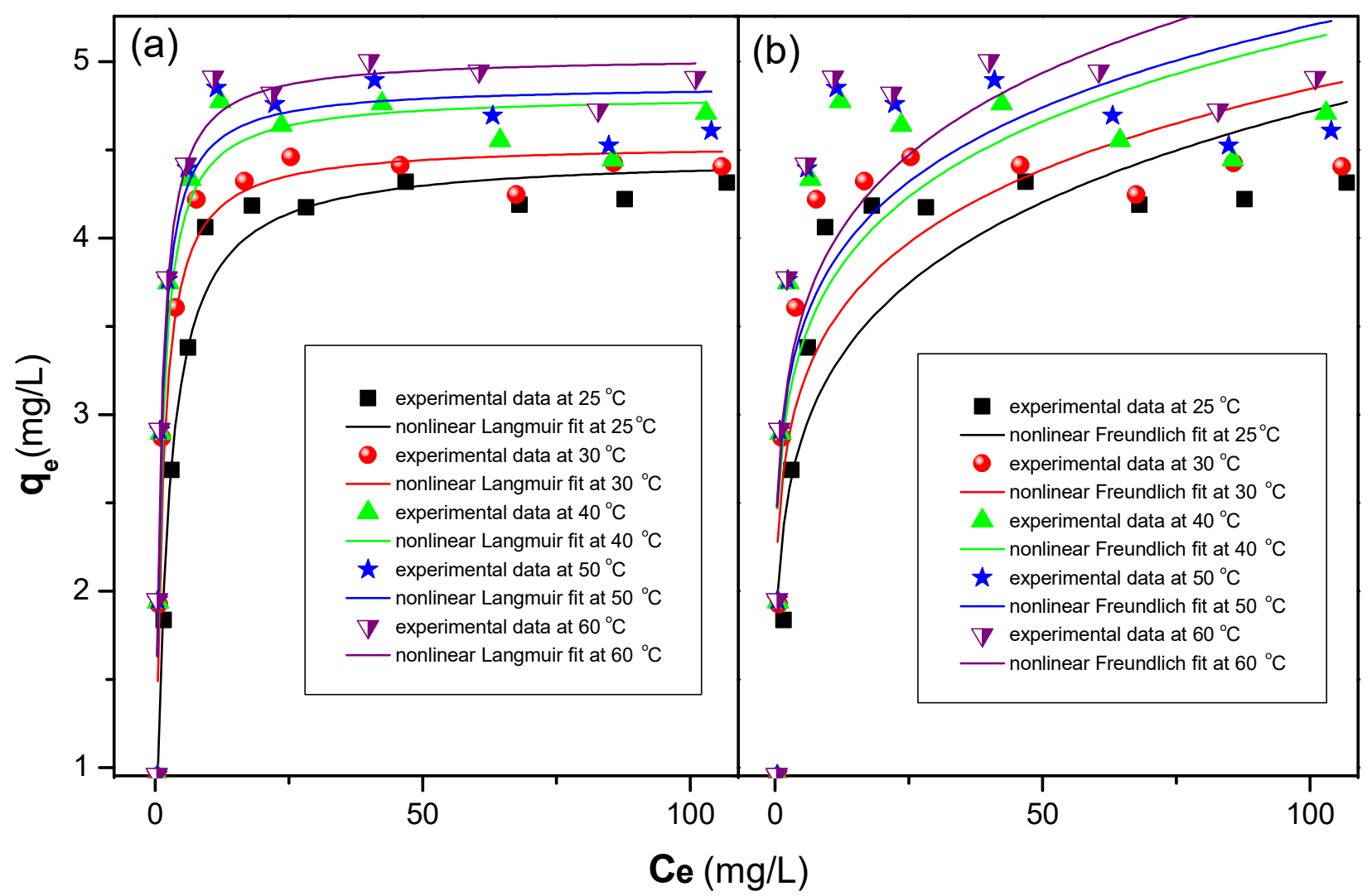

Figure 5: Adsorption equilibrium isotherm of $M B$ dye on $A C, p H 5.01 ; C_{i} 20 \mathrm{mg} / \mathrm{L}$; and contact time 120 min. (a) Langmuir isotherm, (b) Freundlich isotherm.

Table 2: Isotherm parameters for adsorption of methylene blue on $A C$ at $25^{\circ} \mathrm{C}$.

\begin{tabular}{|c|c|c|c|c|c|c|c|c|c|}
\hline \multirow[b]{2}{*}{$\begin{array}{l}\mathbf{T} \\
{ }^{\circ} \mathrm{C}\end{array}$} & \multicolumn{5}{|c|}{ Langmuir parameters } & \multicolumn{4}{|c|}{ Freundlich parameters } \\
\hline & $\begin{array}{c}\mathbf{Q}_{\max } \\
(\mathrm{mg} / \mathrm{g})\end{array}$ & $\begin{array}{c}\mathbf{K}_{\mathrm{L}} \\
(\mathrm{L} / \mathrm{mg})\end{array}$ & $x^{2}$ & $\mathbf{R}^{2}$ & $\mathbf{R}_{\mathbf{L}}$ & $\begin{array}{c}\mathbf{K}_{\mathbf{F}} \\
(\mathrm{mg} / \mathrm{g}) /(\mathrm{mg} / \mathrm{L})^{\mathrm{n}}\end{array}$ & 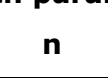 & $x^{2}$ & $\mathbf{R}^{\mathbf{2}}$ \\
\hline 25 & 4.47 & 0.50 & 0.027 & 0.979 & $0.167-0.013$ & 2.189 & 0.167 & 0.366 & 0.729 \\
\hline 30 & 4.54 & 0.95 & 0.059 & 0.959 & $0.095-0.007$ & 2.507 & 0.143 & 0.456 & 0.683 \\
\hline 40 & 4.81 & 1.07 & 0.107 & 0.937 & $0.085-0.000$ & 2.710 & 0.139 & 0.610 & 0.643 \\
\hline 50 & 4.87 & 1.23 & 0.095 & 0.947 & $0.075-0.005$ & 2.800 & 0.135 & 0.643 & 0.639 \\
\hline 60 & 5.03 & 1.22 & 0.083 & 0.958 & $0.076-0.005$ & 2.827 & 0.142 & 0.602 & 0.692 \\
\hline
\end{tabular}

\section{Kinetics of Adsorption}

The study of adsorption kinetic provides precious information about the mechanism of the adsorption process. Numerous kinetic models were developed to obtain essential real values of the adsorption kinetic constants. In the present study, two wellknown kinetic models (pseudo-first-order 'PFO' and pseudo-second-order 'PSO') and the general-order kinetic equation, $\mathrm{GO}$, were utilized to discuss the adsorption kinetic of $M B$ onto $A C$. The kinetic experiments implemented at the optimal conditions $\left(\mathrm{pH} \sim 5\right.$, initial concentration of dye, $\mathrm{C}_{\mathrm{i}} 20 \mathrm{mg} / \mathrm{L}$, AC particles with $125 \mu \mathrm{m}$, and contact time of $2 \mathrm{~h}$ ) at temperatures of $35^{\circ} \mathrm{C}$ and $60{ }^{\circ} \mathrm{C}$. The common mistake in analyzing adsorption kinetics data is the use of linearized forms of kinetic models due to complexities associated with recognizing the error structure in the data when converting a nonlinear equation into a linear equation using various transformations and the extent to which mathematical manipulation of the data influences the structure of the equation (46). Linearization requires an equal variance for all $q_{t}$ values through the data set, which is really not equal in complete range. This might consequence in an incorrect assessment of the best fit as evaluated by the correlation coefficient $(R)$, resulting in an error in the determination coefficient $\left(R^{2}\right)$ as well as in the adjusted determination coefficient $\left(R_{\text {adj }}^{2}\right)$. Therefore, higher $\mathrm{R}^{2}$ values do not inevitably mean a better match for experimental data. Nonlinear kinetic models were therefore used in this analysis. The fitting results of experimental data and the predicted nonlinear PSO plot of adsorption of $M B$ dye onto $\mathrm{AC}$ at $\mathrm{pH} 5.0$ and temperatures of $35^{\circ} \mathrm{C}$ and $60{ }^{\circ} \mathrm{C}$ were presented in Figure 6 (a). The experimental data and nonlinear PFO, and the GO kinetic plots for the same data and conditions were shown in Figure 6 (b) and Figure 7, respectively. Moreover, the kinetic parameters; $\mathrm{k}_{2}, \mathrm{k}_{1}, \mathrm{k}_{\mathrm{N}}, \mathrm{q}_{\mathrm{e}}$, and $n$, along with the values of statistical parameters, were enlisted in Table 3. It is evident, 
from the results, that the relatively higher $\mathrm{R}^{2}$ adj and lower $\mathrm{x}^{2}$ values of the nonlinear PSO equation compared to that of the PFO confirm the nonlinear PSO kinetic expression as the best-fit expression to represent the kinetic uptake of $\mathrm{MB}$ onto prepared $A C$. The adjusted determination coefficients $\left(R^{2}{ }_{\text {adj }}\right)$ for the PSO model (0.9348 and 0.9626 at 208 and $333 \mathrm{~K}$ respectively) were much more significant than that for the PFO model (0.6854 and 0.8538), indicating that $\mathrm{MB}$ adsorption onto $\mathrm{AC}$ can be explained as a pseudo-second-order model. Furthermore, the low values of reduced chi-square $\left(x^{2}\right)$ for PSO fit $(0.0026$ and 0.0027$)$ compared with that of PFO (0.0124 and 0.0106$)$ indicate that the adsorption capacities, $\mathrm{q}_{\mathrm{e} ; \mathrm{cal}}$, calculated by PSO

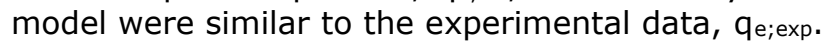
For the plots shown in Figure 7, the general-order adsorption kinetics model at $333 \mathrm{~K}$ showed low $x^{2}$ values (0.0026), and high $\mathrm{R}^{2}$ adj value $(0.964)$, the adsorption uptake at equilibrium $\left(\mathrm{q}_{\mathrm{e}}\right)$ is 2.00611 $\mathrm{mg} / \mathrm{g}$, the constant rate $\mathrm{k}_{\mathrm{N}}$ is 0.60946 ( $\mathrm{g} / \mathrm{mg}$ )1.8574/min and the order of kinetic model $(n)$ is 1.8574 . The value of $n(1.86)$ is closer to 2 than 1 , reinforcing the previous observation that the PSO kinetic model presented best-fit than PFO. Thus, the n-value of 1.857 may as well be due to changes in adsorption kinetics from PSO to PFO during the adsorbate-adsorbent contact period. Therefore, it can be possible to characterize the MB adsorption onto $\mathrm{AC}$ as a pseudo-second-order model. It can be inferred that the adsorption process can take place faster at elevated temperatures based on the adsorption rate constant of PSO, $\mathrm{k}_{2}$, at $308 \mathrm{~K}$ and $333 \mathrm{~K}$.

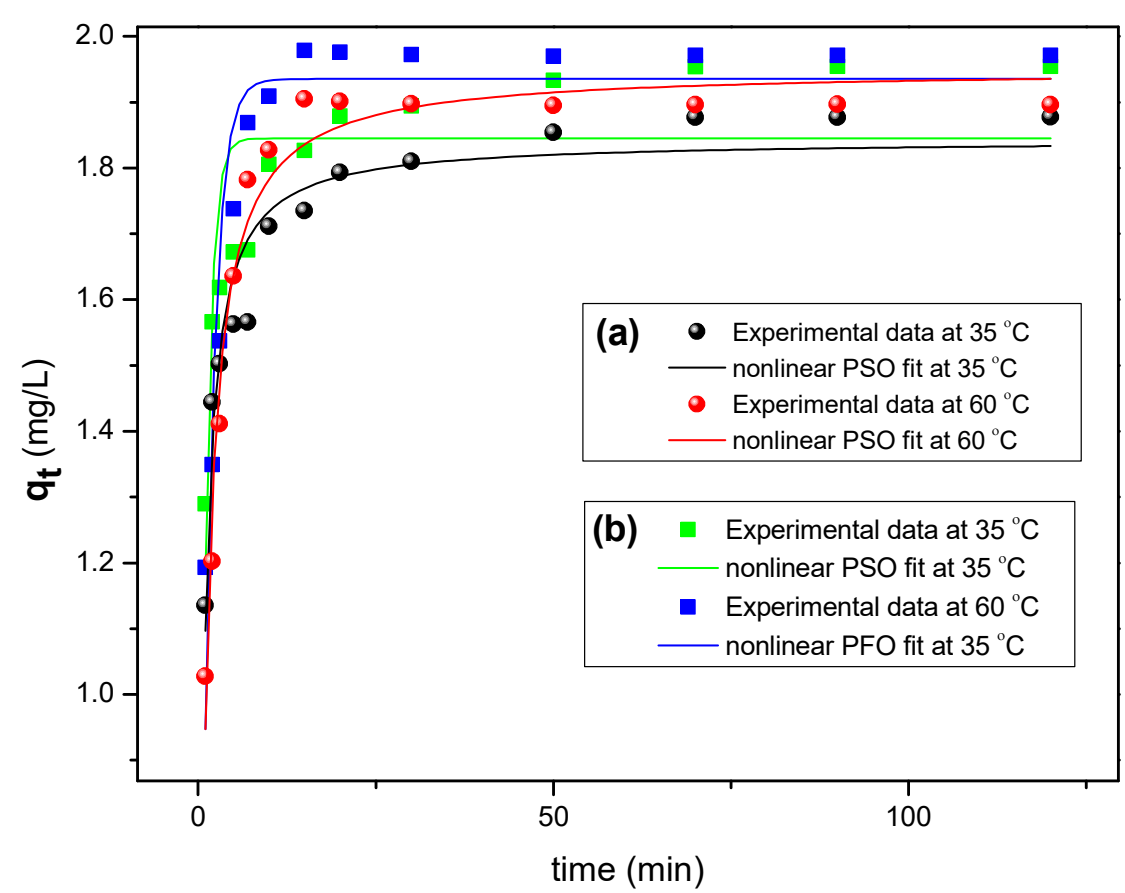

Figure 6: Application of kinetic models for adsorption of MB onto AC at 35 and $60{ }^{\circ} \mathrm{C}$. (a) Nonlinear pseudo-second-order fit (b) Nonlinear pseudo-first-order fit. 


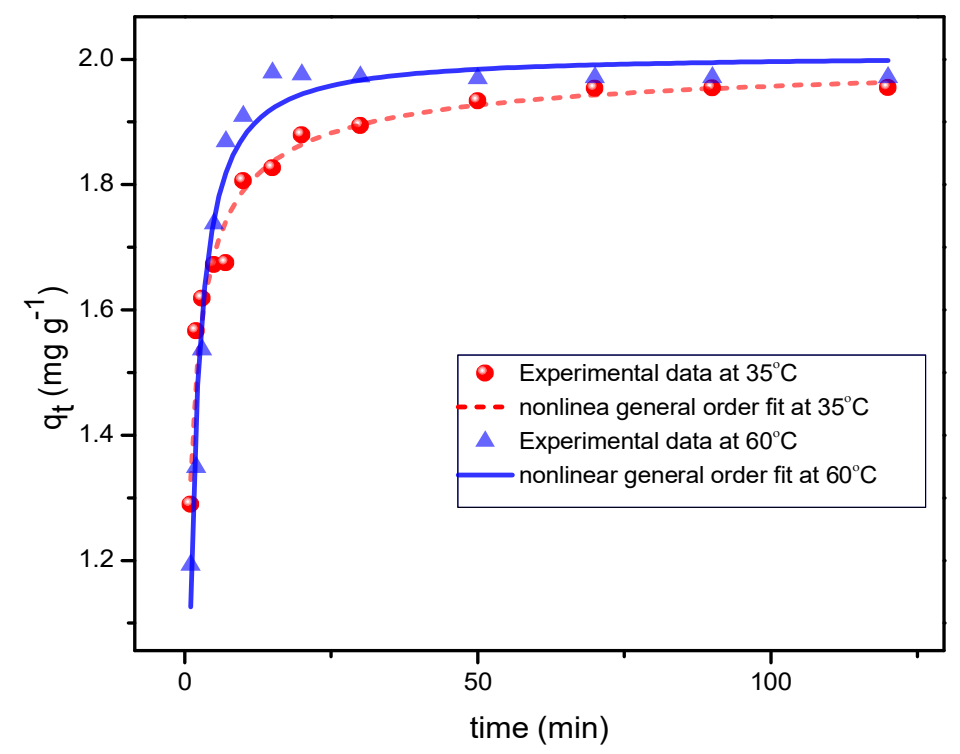

Figure 7: Nonlinear general-order fit for sorption of $M B$ onto $A C\left(35\right.$ and $60^{\circ} \mathrm{C}$ ).

Table 3: Kinetic parameters for the adsorption of $M B$ onto $A C$ at various conditions from a nonlinear

\begin{tabular}{|c|c|c|c|c|}
\hline \multirow[t]{2}{*}{ Parameter } & \multicolumn{2}{|c|}{ At $308 \mathrm{~K}$} & \multicolumn{2}{|c|}{ At $333 \mathrm{~K}$} \\
\hline & $\begin{array}{l}\text { Value } \\
20.00\end{array}$ & Standard Error & $\begin{array}{l}\text { Value } \\
20.00\end{array}$ & Standard Error \\
\hline $\begin{array}{l}\text { qe,exp }(\mathrm{mg} / \mathrm{g}) \\
\text { Pseudo-second-or }\end{array}$ & 1.77 & 0.19 & 1.80 & 0.27 \\
\hline $\begin{array}{l}\mathrm{q}_{\mathrm{e}, \text { cal }}(\mathrm{mg} / \mathrm{g}) \\
\mathrm{k}_{2}(\mathrm{~g} / \mathrm{mg} . \mathrm{min} .)\end{array}$ & $\begin{array}{c}1.92 \\
0.6178\end{array}$ & $\begin{array}{c}0.02 \\
0.1032\end{array}$ & $\begin{array}{c}2.02 \\
0.9760\end{array}$ & $\begin{array}{c}0.02 \\
0.0546\end{array}$ \\
\hline$R_{\text {adj }}^{2}$ & 0.9348 & & 0.9626 & \\
\hline $\begin{array}{l}x^{2} \\
\text { Pseudo-first-orde }\end{array}$ & 0.0026 & & 0.0027 & \\
\hline $\begin{array}{l}\mathrm{q}_{\mathrm{e}, \text { cal }}(\mathrm{mg} / \mathrm{g}) \\
\mathrm{k}_{1}\left(\mathrm{~min}^{-1}\right)\end{array}$ & $\begin{array}{c}1.85 \\
1.0325\end{array}$ & $\begin{array}{c}0.03 \\
0.1432\end{array}$ & $\begin{array}{l}1.9355 \\
0.6726\end{array}$ & $\begin{array}{l}0.03362 \\
0.06926\end{array}$ \\
\hline$R_{\mathrm{adj}}^{2}$ & 0.6854 & & 0.8538 & \\
\hline$x^{2}$ & 0.0124 & & 0.0106 & \\
\hline General-order & & & & \\
\hline $\begin{array}{l}\mathrm{q}_{\mathrm{e}, \mathrm{cal}}(\mathrm{mg} / \mathrm{g}) \\
\mathrm{k}_{\mathrm{N}}((\mathrm{g} / \mathrm{mg}) \mathrm{n} / \mathrm{min} .) \\
\mathrm{N}\end{array}$ & $\begin{array}{c}2.01846 \\
0.4899 \\
2.71673\end{array}$ & $\begin{array}{l}0.04743 \\
0.13874 \\
0.38239\end{array}$ & $\begin{array}{c}2.00611 \\
0.60946 \\
1.8574\end{array}$ & $\begin{array}{c}0.03052 \\
0.06289 \\
0.1792\end{array}$ \\
\hline$R_{a d j}^{2}$ & 0.96922 & & 0.96402 & \\
\hline$x^{2}$ & 0.00122 & & 0.00261 & \\
\hline
\end{tabular}

\section{Diffusion Study}

The diffusion mechanism of MB adsorption onto the $A C$ was explored using linearized transformation of the intra-particle diffusion model presented in Equation (19).

$$
q_{t}=k_{P} \sqrt{t}+C
$$

Where $k_{p}\left(\mathrm{mg} / \mathrm{g} \mathrm{min}^{1 / 2}\right)$ is the rate constant of the intra-particle diffusion and $C(\mathrm{mg} / \mathrm{g})$ is a constant associated with the thickness of the boundary layer. The fitting of the kinetic data into the intraparticle diffusion model can be useful for identifying the adsorption mechanisms and predicting the rate limiting step of the adsorption process. In general there are four steps involved in transport processes during adsorption by porous adsorbents were proposed: (a) bulk transport of adsorbate in the solution phase to the liquid film enclosing the adsorbent, which can occur very fast, therefore it has no effect in kinetic. (b) film diffusion or boundary layer diffusion (occurs slowly) in which the adsorbate transport from the bulk liquid phase across the hydrodynamic boundary film to the external surface of the adsorbent. (d) intra-particle diffusion (occurs 
slowly); here the adsorbate molecules transport from exterior surface of the adsorbent into the pores of the adsorbent. (e) adsorptive attachment of adsorbate onto active sites often occurs very quickly; therefore, it is also not significant for kinetic design $(16,17)$.

To determine the rate-controlling step and hence to interpret the mechanism of adsorption process, the intra-particle diffusion model was engaged and the results were showed in Figure 8. The plots of adsorbate uptake $\left(\mathrm{q}_{\mathrm{t}}\right)$ against the square root of time $(\sqrt{ } t)$ exhibited two different linear portions, and do not pass through the origin. Such a deviation of the straight line from the origin may be considered due to the difference in the rate of diffusion of the dye molecules at the initial stage of the process. The intercepts of the plots (C) (Table 4) are 1.53 and $1.64 \mathrm{mg} / \mathrm{g}$ at $35^{\circ} \mathrm{C}$ and $60^{\circ} \mathrm{C}$ respectively. The multiple linear regions plot revelled that the adsorption process is controlled by a multisteps mechanism not only governed by intra-particle diffusion because the lines do not pass through the origin. This indicates that the rate controlling steps involve film diffusion step and intra-particle diffusion step. Moreover, the value of $C$ reflects the boundary layer thickness effect. It observed that the boundary layer effect slightly increases with the temperature. The first portion of linear regions in the plot is attributed to the liquid-film diffusion mass transfer; whereas the second linear portion indicates that the intraparticle diffusion of the dye molecules into the pores of the AC controls the adsorption process (41). Intra-particle diffusion rate constants obtained for different temperatures are $4.99 \times 10^{-}$ 2 and $4.20 \times 10^{-2} \mathrm{mg} / \mathrm{g} \mathrm{m^{1/2 }}$ at $35^{\circ} \mathrm{C}$ and $60^{\circ} \mathrm{C}$, respectively (Table 4 ).

The mechanism of adsorption of MB from aqueous solutions onto $A C$ is controlled by two slow steps of film diffusion and intra-particle diffusion. The first step of bulk transport of MB molecules in the solution phase is considered as fast process, also the last step of adsorption of adsorbate onto internal active sites is occurs very fast.

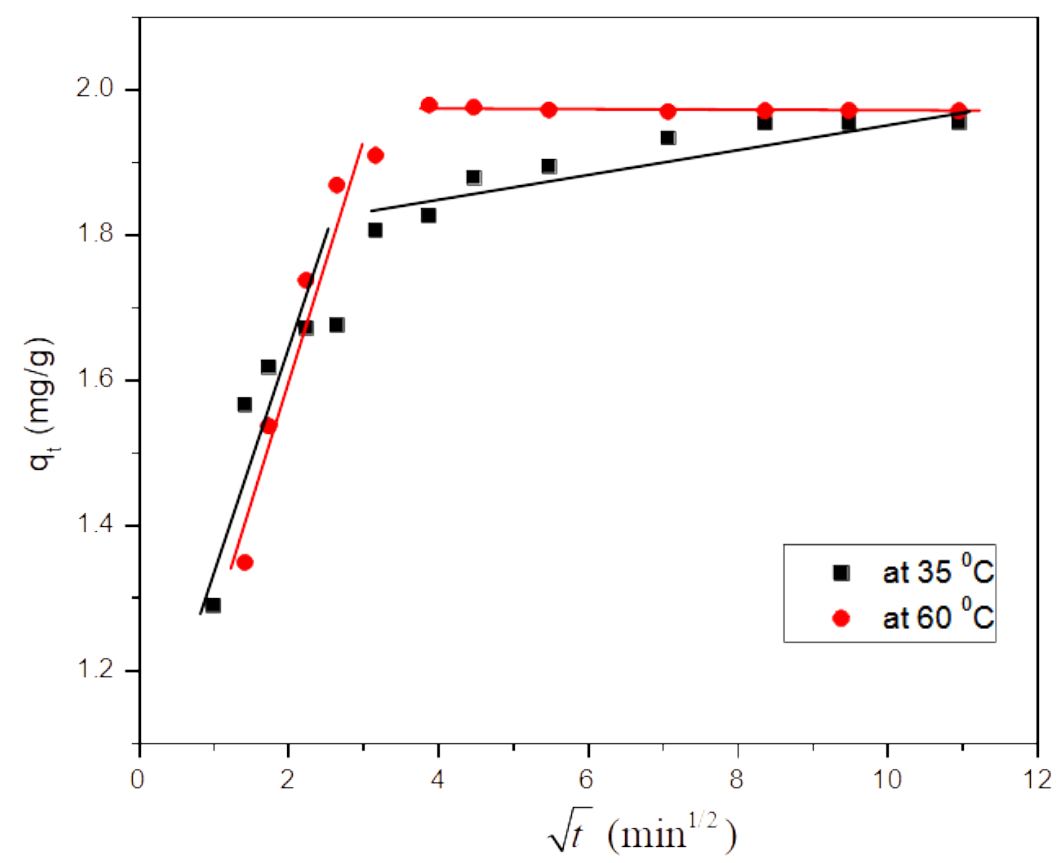

Figure 8: Intra-particle diffusion plot for $\mathrm{MB}$ adsorption onto $\mathrm{AC}$ at $35^{\circ} \mathrm{C}$ and $60^{\circ} \mathrm{C}$.

Table 4: Intraparticle diffusion model parameters

\begin{tabular}{lll}
\hline & $\mathbf{K}_{\mathbf{p}}$ (Slope) & $\mathbf{C}$ (Intercept) \\
\hline At $35{ }^{\circ} \mathrm{C}$ & 0.04987 & 1.53348 \\
At $60{ }^{\circ} \mathrm{C}$ & 0.04199 & 1.63795 \\
\hline
\end{tabular}

\section{Thermodynamic Parameters}

Thermodynamic studies are a crucial element of predicting adsorption mechanisms (physisorption and chemisorption). The thermodynamic parameters can be determined along with thermodynamics laws using Equations 15, 16, and 17. The precise assessment of thermodynamic parameters obviously depends directly on the precise calculation of the equilibrium constant among the two phases ( $\mathrm{K}_{\mathrm{c}}$; dimensionless). The thermodynamic equilibrium constant $K_{c}$ values can be obtained from adsorption-isotherm constants or partition coefficient values $(50,51)$. Accordingly, the $K_{c}$ value can be determined from the nonlinear 
isotherm equilibrium model constant, which provides best fit for the empirical data (46). Thus, $\mathrm{K}_{\mathrm{C}}$ was calculated from the Langmuir model constant of adsorption equilibrium, $\mathrm{K}_{\mathrm{L}}(\mathrm{L} / \mathrm{mg})$ using Equation 20, taking into account the approbate unit conversion $(31,52)$ :

$$
K_{C}=M_{w} \times 55.5 \times 1000 \times K_{L}
$$

The factor 55.5 is number of moles of pure water per liter; $M_{w},(\mathrm{~g} / \mathrm{mol}$.$) is adsorbate's molecular$ weight, methylene blue $\left(M_{w}=319.85 \mathrm{~g} / \mathrm{mol}\right.$. $)$.

Combining Equation 15 and Equation 20 gives:

$$
\Delta G^{0}=-R T \ln \left(M_{W} \times 55.5 \times 1000 \times K_{L}\right)
$$

The values of the parameters $\Delta H^{\circ}$ and $\Delta S^{\circ}$ can be computed from the slope and intercept of Van't Hoff equation, Equation 17, respectively. Figure 9 shows the dependence of equilibrium constant on temperature, and Table 5 summarized the information on the thermodynamic parameters of $\mathrm{MB}$ adsorption onto the AC process.

The adsorption can be categorized, to a certain point, by the magnitude of enthalpy change. Physisorption, such as van der Waals interaction, characterized by low enthalpy change $<20 \mathrm{~kJ} / \mathrm{mol}$, electrostatic interaction ranges from 20 to 80 $\mathrm{kJ} / \mathrm{mol}$, and chemisorption bond strengths can be $80-450 \mathrm{~kJ} / \mathrm{mol}(53,54)$. The positive value of $\Delta H^{\circ} \quad(7.53 \mathrm{~kJ} / \mathrm{mol})$ suggests the endothermic nature of the process (23), which was further exhibited with an increase in both adsorption capacity (Figure 5 and Table 2) and equilibrium constant (Table 5) as temperature rise. Furthermore, the amount of enthalpy was steady with Van der Waals force (55).

The negative values of $\Delta G^{\circ}$ of $M B$ adsorption onto $A C$ at all investigated temperatures suggest that the adsorption phenomenon occurred favorably and spontaneously with minimal requirements of the adsorption and activation energies. This conclusion was in good agreement with the conclusions drawn from the separation factor analysis $\left(0<R_{L}<1\right)$. Additionally, the $\Delta G^{\circ}$ and $K_{C}$ values dramatically increased as the examination temperatures increased from 30 to $50{ }^{\circ} \mathrm{C}$, demonstrating more energetically favorable adsorption at elevated temperatures.
Furthermore, Nollet, Roels (56) showed that the physisorption process typically had an activation energy of $5-40 \mathrm{~kJ} / \mathrm{mol}$, whereas chemisorption had relatively higher activation energy (40 - 800 $\mathrm{kJ} / \mathrm{mol})$. Hence, the values of $\Delta \mathrm{H}^{\circ}$ and $\Delta \mathrm{G}^{\circ}$ suggest that a physisorption process drove the adsorption of MB dye onto AC. Simultaneously, the positive value of $\Delta \mathrm{S}^{\circ}$ confirmed the increased arbitrariness at the solid-solute interface throughout adsorption and spontaneity of the process. From a thermodynamic point of view, entropy appears to be the driving force for adsorption $(57,58)$.

\section{Determination of Activation Energy}

The activation energy for the MB dye adsorption process into $A C$ was estimated from the values of the rate constants at 333 and $308 \mathrm{~K}$ using Arrhenius equation as follows $(53,59)$ :

$$
\begin{gathered}
k=A e^{-E_{a} R T} \\
E_{a}=\frac{R \ln \left(\frac{k_{2}}{k_{1}}\right)}{\left(\frac{1}{T_{1}}+\frac{1}{T_{2}}\right)}
\end{gathered}
$$

Where $E_{a}$ is the activation energy of the adsorption in $\mathrm{J} / \mathrm{mol} ; \mathrm{k}_{1}$ and $\mathrm{k}_{2}$ are the rate constant obtained from nonlinear analysis according to the PSO at temperatures of $T_{1}$ and $T_{2}(K)$ respectively; $A$ is the Arrhenius constant, temperature-independent factor in ( $\mathrm{g} / \mathrm{mg}$. min.); $\mathrm{R}$ is the universal gas constant $(8.314 \mathrm{~J} / \mathrm{mol}$. K). The activation energy value, computed according to the Arrhenius equation, was $15.6 \mathrm{~kJ} / \mathrm{mol}$ using $20 \mathrm{mg} / \mathrm{L}$ initial concentration of $\mathrm{MB}$, where it is of the similar magnitude as the activation energy of activated chemical sorption. The positive value of $E_{a}$ suggested that temperature rise assists the adsorption. However, the obedience of the experimental data to PSO kinetic model in addition to the value of $E_{a}$ of the process does not necessarily suggest that the adsorption process is chemisorption. It is essential to demonstrate the formation of such chemical bonds using specific analytical techniques (FTIR, Raman spectroscopy, and so on) merged with thermodynamic parameters of enthalpy and entropy changes to decide whether the process is chemisorption or physisorption. 


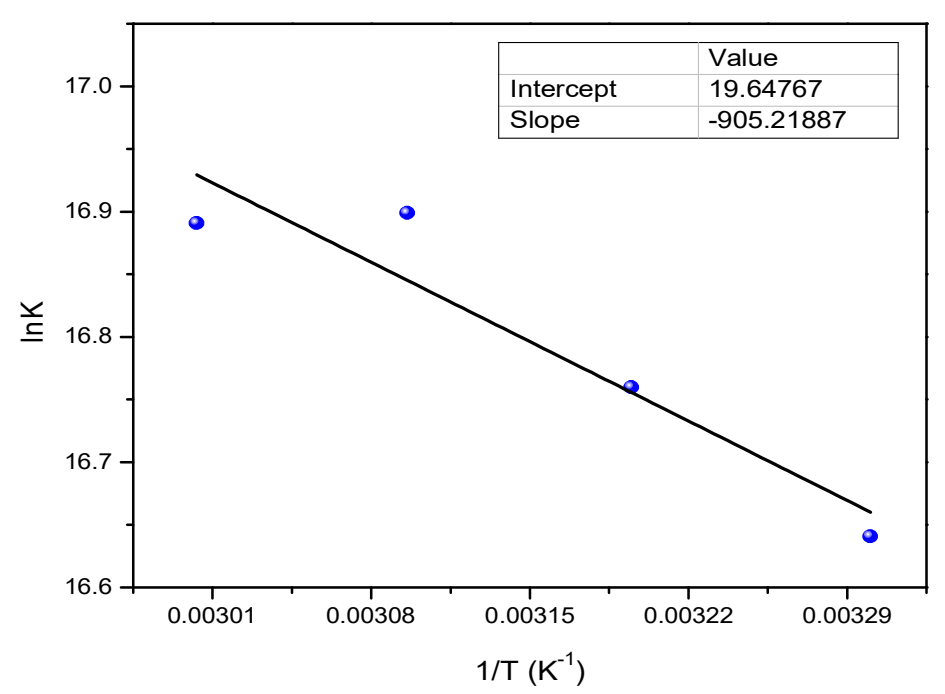

Figure 9: Van't Hoff plot for adsorption of MB dye onto AC.

Table 5: Thermodynamic parameters for adsorption of MB onto the synthesized AC.

\begin{tabular}{ccccc}
\hline $\mathrm{T}(\mathrm{K})$ & $\mathrm{K}_{\mathrm{c}}$ & $\Delta \mathrm{G}^{\circ}(\mathrm{kJ} / \mathrm{mol})$ & $\Delta \mathrm{H}^{\circ}(\mathrm{kJ} / \mathrm{mol})$ & $\Delta \mathrm{S}^{\circ}(\mathrm{J} / \mathrm{mol} . \mathrm{K})$ \\
\hline 298 & 8875838 & -39.64 & & \\
303 & 16864091 & -41.92 & 7.53 & 163.35 \\
313 & 18994292 & -43.61 & & \\
323 & 21834560 & -45.38 & & \\
333 & 21657044 & -46.76 & & \\
\hline
\end{tabular}

\section{CONCLUSION}

The adsorption of methylene blue from aqueous solution onto activated carbon prepared from pomegranate peel was investigated. The equilibrium isotherm, kinetics, and thermodynamics parameters of adsorption were determined using nonlinear regression analysis. The system attained equilibrium state after 50 minutes with a removal\% of $>96.5 \%$. The maximum uptake of $\mathrm{MB}$ at equilibrium $\left(\mathrm{q}_{\mathrm{e}}=5.03\right.$ $\mathrm{mg} / \mathrm{g}$ ) was observed at $60{ }^{\circ} \mathrm{C}$ susing $90 \mathrm{mg} / \mathrm{L}$ initial concentration of dye solution and $125 \mu \mathrm{m}$ particle size of adsorbent. The adsorption equilibrium study revealed that the Langmuir model was best fitted to the equilibrium data of adsorption, Langmuir constant $\mathrm{K}_{\mathrm{L}}=1.22 \mathrm{~L} / \mathrm{mg}$ at $60{ }^{\circ} \mathrm{C}$. The kinetic data has been best explained by pseudo-second-order kinetic model $\left(R 2_{a d j}=0.9626\right.$ and $x^{2}=0.0027$ at $333 \mathrm{~K}$ ). The mechanism of adsorption process involve both external film diffusion and intra-particle or pore diffusion as limitting steps. The values of the thermodynamic equilibrium constant $\left(\mathrm{K}_{\mathrm{C}}\right)$ were determned from Langmuir adsorption-isotherm constants. The thermodynamics parameters showed that the adsorption of $\mathrm{MB}$ onto $\mathrm{AC}$ was spontaneous $\left(\Delta \mathrm{G}^{\circ}\right.$ between - $39.64 \mathrm{~kJ} / \mathrm{mol}$ to $-46.76 \mathrm{~kJ} / \mathrm{mol}$ ) and endothermic $\left(\Delta \mathrm{H}^{\circ}=+7.53 \mathrm{~kJ} / \mathrm{mol}\right)$ in nature. Moreover, the $\left(+\Delta \mathrm{S}^{\circ}\right)$ value $(163.35 \mathrm{~J} / \mathrm{mol} . \mathrm{K})$ indicated an increased randomness at the solidsolution interface during the adsorption process.

\section{ACKNOWLEDGMENTS}

The authors express their sincere gratitude to the Department of Applied Chemistry, International University of Africa, in Sudan, for financially supporting this study.

\section{AUTHORS CONTRIBUTION STATEMENT}

Ibrahim Y. Erwa conceptualized and designed this work. Omar A. Alrefaei and Issa M. Hassan conducted the experimental works and prepared the draft of the manuscript. Omer A. Ishag manages literature review and revised manuscripts. All authors discussed the methodology and results and approved the final manuscript.

\section{CONFLICT OF INTEREST}

The authors declare no conflict of interest.

\section{REFERENCES}

1. Kanakaraju D, Yahya MS, Wong S-P. Removal of chemical oxygen demand from agro effluent by $\mathrm{ZnO}$ photocatalysis and photo-Fenton. SN Appl Sci. 2019 Jul;1(7):738. <DOI $>$.

2. Bolisetty S, Peydayesh M, Mezzenga R. Sustainable technologies for water purification from heavy metals: review and analysis. Chem Soc Rev. 2019;48(2):463-87. $\leq \mathrm{DOI}>$. 
3. Haseena M, Malik MF, Javed A, Arshad S, Asif N, Zulfiqar $S$, et al. Water pollution and human health. Environmental Risk Assessment and Remediation. 2017;1(3):16-9. $\leq$ DOI $>$.

4. Guivarch E, Trevin S, Lahitte C, Oturan MA. Degradation of azo dyes in water by Electro-Fenton process. Environmental Chemistry Letters. 2003 Mar $1 ; 1(1): 38-44 . \leq \mathrm{DOI}>$.

5. Tara N, Siddiqui SI, Rathi G, Chaudhry SA, Inamuddin, Asiri AM. Nano-engineered Adsorbent for the Removal of Dyes from Water: A Review. CAC. 2020 Jan 8;16(1):1440. $\leq \mathrm{DOI}>$.

6. Dawood S, Sen T. Review on Dye Removal from Its Aqueous Solution into Alternative Cost Ef- fective and Non-Conventional Adsorbents. Journal of Chemical and Process Engineering. 2014;1(104):1-11.

7. Rafatullah Mohd, Sulaiman $O$, Hashim R, Ahmad A. Adsorption of methylene blue on low-cost adsorbents: A review. Journal of Hazardous Materials. 2010 May;177(13): $70-80 . \leq$ DOI $>$.

8. Gupta VK, Kumar R, Nayak A, Saleh TA, Barakat MA. Adsorptive removal of dyes from aqueous solution onto carbon nanotubes: A review. Advances in Colloid and Interface Science. 2013 Jun;193-194:24-34. <DOI>.

9. Babu BR, Parande A, Raghu S, Kumar TP. Textile technology-an overview of wastes produced during cotton textile processing and effluent treatment methods. Journal of Cotton Sciences. 2007;11:110.

10. Kasih TP, Kharisma A, Perdana MK, Murphiyanto RDJ. Development of non-thermal plasma jet and its potential application for color degradation of organic pollutant in wastewater treatment. IOP Conference Series: Earth and Environmental Science. 2017 Dec;109:012004. <DOI>.

11. Beluci $N$ de $C L$, Mateus GAP, Miyashiro CS, Homem NC, Gomes RG, Fagundes-Klen MR, et al. Hybrid treatment of coagulation/flocculation process followed by ultrafiltration in TIO2-modified membranes to improve the removal of reactive black 5 dye. Science of The Total Environment. 2019 May;664:222-9. <DOI>.

12. Erwa IY, Ibrahim AA. Removal of chromium (VI) ions from aqueous solution using wood sawdust as adsorbent. Journal of Natural and Medical Sciences. 2016;17(2):112.

13. Jawad AH, Abdulhameed AS, Mastuli MS. Acidfactionalized biomass material for methylene blue dye removal: a comprehensive adsorption and mechanism study. Journal of Taibah University for Science. 2020 Jan $1 ; 14(1): 305-13$. $\leq$ DOI $>$.

14. Segun Esan O, Nurudeen Abiola O, Owoyomi O, Olumuyiwa Aboluwoye C, Olubunmi Osundiya $M$. Adsorption of Brilliant Green onto Luffa Cylindrical Sponge: Equilibrium, Kinetics, and Thermodynamic Studies. ISRN Physical Chemistry. 2014 Mar 4;2014:112. $\leq \mathrm{DOI}>$.

15. Mahmoud ME, Nabil GM, Khalifa MA, El-Mallah NM, Hassouba HM. Effective removal of crystal violet and methylene blue dyes from water by surface functionalized zirconium silicate nanocomposite. Journal of Environmental Chemical Engineering. 2019 Apr;7(2):103009. <DOI $>$.

16. Yunusa $U$, Usman B, IbrahiM M. Modeling and Regeneration Studies for the Removal of Crystal Violet Using Balanites aegyptiaca Seed Shell Activated Carbon. JOTCSA. 2020 Dec 29;8(1):197-210. <DOI>.

17. Felix N, Ienna N, Ikelle I, Anselm O, Nwabueze E, Emeka I, et al. Activated Plantain Peel Biochar As Adsorbent For Removal of Zinc(II) Ions From Aqueous Solution: Equilibrium and Kinetics Studies. JOTCSA. 2018 Oct $30 ; 5(3): 1257-70 . \leq$ DOI $>$.

18. Gökirmak Söğüt E, Çalişkan Kiliç N. Equilibrium and Kinetic Studies of a Cationic Dye Adsorption Onto Raw Clay. JOTCSA. 2020 Jul 13;7(3):713-26. $\leq$ DOI $>$.

19. He Y-C, Yang J, Kan W-Q, Zhang H-M, Liu Y-Y, Ma J$F$. A new microporous anionic metal-organic framework as a platform for highly selective adsorption and separation of organic dyes. J Mater Chem A. 2015;3(4):1675-81. <DOI>.

20. Huber F, Berwanger J, Polesya S, Mankovsky S, Ebert $\mathrm{H}$, Giessibl FJ. Chemical bond formation showing a transition from physisorption to chemisorption. Science. 2019 Oct $11 ; 366(6462): 235-8$. $\leq$ DOI $>$.

21. Kosheleva RI, Mitropoulos AC, Kyzas GZ. Synthesis of activated carbon from food waste. Environ Chem Lett. 2019 Mar;17(1):429-38. <DOI>.

22. Heidarinejad Z, Dehghani MH, Heidari M, Javedan G, Ali I, Sillanpää M. Methods for preparation and activation of activated carbon: a review. Environ Chem Lett. 2020 Mar;18(2):393-415. <DOI $>$.

23. Ali AF, Kovo AS, Adetunji SA. Methylene Blue and Brilliant Green Dyes Removal from Aqueous Solution Using Agricultural Wastes Activated Carbon. JEAS. 2017;07(02):95-107. <DOI>.

24. Ponnusami V, Krithika V, Madhuram R, Srivastava $\mathrm{SN}$. Biosorption of reactive dye using acid-treated rice husk: Factorial design analysis. Journal of Hazardous Materials. 2007 Apr;142(1-2):397-403. <DOI 2.

25. Bharti V, Vikrant K, Goswami M, Tiwari H, Sonwani $\mathrm{RK}$, Lee $\mathrm{J}$, et al. Biodegradation of methylene blue dye in a batch and continuous mode using biochar as packing media. Environmental Research. 2019 Apr;171:356-64. $\leq \mathrm{DOI}>$.

26. Clifton JI, Leikin JB. Methylene Blue. American Journal of Therapeutics. 2003;10(4):289-91. <URL>.

27. Hama Aziz KH, Mahyar A, Miessner $H$, Mueller $S$, Kalass D, Moeller D, et al. Application of a planar falling film reactor for decomposition and mineralization of methylene blue in the aqueous media via ozonation, Fenton, photocatalysis and non-thermal plasma: A comparative study. Process Safety and Environmental Protection. 2018 Jan;113:319-29. <DOI>.

28. Yagub MT, Sen TK, Ang HM. Equilibrium, Kinetics, and Thermodynamics of Methylene Blue Adsorption by 
Pine Tree Leaves. Water Air Soil Pollut. 2012 Oct;223(8):5267-82. <DOI>.

29. Dekhyl A, Mohamed H, Alwan L. Preparation of activated charcoal as a new adsorbent from the natural plant sources. Tikrit Journal of Pure Science. 2017;22(10):110-5. $\leq U R L>$.

30. Sogbochi E. Evaluation of Adsorption Capacity of Methylene Blue in Aqueous Medium by Two Adsorbents: The Raw Hull of \&lt;i\&gt; Lophira Lanceolata\&lt;/i\&gt; and Its Activated Carbon. AJPC. 2017;6(5):76. <DOI $>$.

31. Tran HN, You S-J, Chao H-P. Fast and efficient adsorption of methylene green 5 on activated carbon prepared from new chemical activation method. Journal of Environmental Management. 2017 Mar;188:322-36. $\leq \underline{\mathrm{DOI}}>$.

32. Yuan N, Cai H, Liu T, Huang Q, Zhang X. Adsorptive removal of methylene blue from aqueous solution using coal fly ash-derived mesoporous silica material. Adsorption Science \& Technology. 2019 May;37(34):333-48. $\leq$ DOI $>$.

33. Tran HN, You S-J, Chao H-P. Thermodynamic parameters of cadmium adsorption onto orange peel calculated from various methods: A comparison study. Journal of Environmental Chemical Engineering. 2016 Sep;4(3):2671-82. <DOI>.

34. Ali MM, Fatthee FE, AbdulkarimThunoon A. Preparation of Activated Carbon from (Punica granatum. sp) Wood by Chemical Treatment Using Potassium Hydroxide. Tikrit Journal of Pure Science. $2019 ; 24(6): 45-50$.

35. Moyo M, Chikazaza L, Nyamunda BC, Guyo U. Adsorption Batch Studies on the Removal of $\mathrm{Pb}$ (II) Using Maize Tassel Based Activated Carbon. Journal of Chemistry. 2013;2013:1-8. <DOI>.

36. Dkheel A-AB. Preparation of A Charcoal From Pine Wood Via Chemical Treatment. Tikrit Journal of Pure Science. 2012;17(3):153-5.

37. Salleh MAM, Mahmoud DK, Karim WAWA, Idris A. Cationic and anionic dye adsorption by agricultural solid wastes: A comprehensive review. Desalination. 2011 Oct;280(1-3):1-13. <DOI>.

38. Zhang Y, Liu J, Du X, Shao W. Preparation of reusable glass hollow fiber membranes and methylene blue adsorption. Journal of the European Ceramic Society. 2019 Dec;39(15):4891-900. <DOI>.

39. Hai TN. Comments on "Effect of Temperature on the Adsorption of Methylene Blue Dye onto Sulfuric AcidTreated Orange Peel." Chemical Engineering Communications. 2017 Jan 2;204(1):134-9. <DOI>.

40. Eren Z, Acar FN. Adsorption of Reactive Black 5 from an aqueous solution: equilibrium and kinetic studies. Desalination. 2006 Jun;194(1-3):1-10. <DOI>.

41. Hamdaoui O, Chiha M. Removal of Methylene Blue from Aqueous Solutions by Wheat Bran. Acta Chim Slov. 2007;54(2):407-18.
42. Kuang $Y$, Zhang $X$, Zhou S. Adsorption of Methylene Blue in Water onto Activated Carbon by Surfactant Modification. Water. 2020 Feb 21;12(2):587. <DOI>.

43. Corda NC, Kini MS. A Review on Adsorption of Cationic Dyes using Activated Carbon. Raghuvir PB, Mathew TM, editors. MATEC Web Conf. 2018;144:02022. $\leq \mathrm{DOI}>$.

44. Rashid RA, Jawad AH, Ishak MAM, Kasim NN. KOHactivated carbon developed from biomass waste: adsorption equilibrium, kinetic and thermodynamic studies for Methylene blue uptake. Desalination and Water Treatment. 2016 Dec 1;57(56):27226-36. <DOI>.

45. El Qada EN, Allen SJ, Walker GM. Adsorption of Methylene Blue onto activated carbon produced from steam activated bituminous coal: A study of equilibrium adsorption isotherm. Chemical Engineering Journal. 2006 Nov; $124(1-3)$ : 103-10. <DOI $>$.

46. Lima ÉC, Adebayo MA, Machado FM. Kinetic and Equilibrium Models of Adsorption. In: Bergmann $\mathrm{CP}$, Machado FM, editors. Carbon Nanomaterials as Adsorbents for Environmental and Biological Applications [Internet]. Cham: Springer International Publishing; 2015 [cited 2021 Dec 5]. p. 33-69. (Carbon Nanostructures). $\leq$ URL $>$.

47. Milonjić SK. Comments on the authors' response to the comments on "Factors influencing the removal of divalent cations by hydroxyapatite", by Smiciklas et al. Journal of Hazardous Materials. 2010 Apr 15;176(13):1126-7. $\leq$ DOI $>$.

48. Kumar KV. Comments on "Adsorption of acid dye onto organobentonite." Journal of Hazardous Materials. 2006 Sep;137(1):638-9. <DOI>.

49. Vasanth Kumar K, Sivanesan S. Equilibrium data, isotherm parameters and process design for partial and complete isotherm of methylene blue onto activated carbon. Journal of Hazardous Materials. 2006 Jun $30 ; 134(1-3): 237-44$. <DOI>.

50. Liu Y. Is the Free Energy Change of Adsorption Correctly Calculated? J Chem Eng Data. 2009 Jul 9;54(7):1981-5. $\leq$ DOI $>$.

51. Doke KM, Khan EM. Adsorption thermodynamics to clean up wastewater; critical review. Reviews in Environmental Science and Bio/Technology. 2013;12(1):25-44. <DOI $>$.

52. Zhou $X$, Zhou $X$. The unit problem in the thermodynamic calculation of adsorption using the Langmuir equation. Chemical Engineering Communications. 2014 Nov 2;201(11):1459-67. <DOI .

53. Machado FM, Bergmann CP, Fernandes THM, Lima $E C$, Royer $B$, Calvete $T$, et al. Adsorption of Reactive Red $M-2 B E$ dye from water solutions by multi-walled carbon nanotubes and activated carbon. Journal of Hazardous Materials. 2011 Sep;192(3):1122-31. <DOI>.

54. Faust SD, Aly OM. Adsorption Processes for Water Treatment. [Internet]. Cambridge: Elsevier Science; 2014 [cited 2021 Dec 5]. ISBN: 978-1-4831-6263-8. 
55. Kuo C-Y, Wu C-H, Wu J-Y. Adsorption of direct dyes from aqueous solutions by carbon nanotubes: Determination of equilibrium, kinetics and thermodynamics parameters. Journal of Colloid and Interface Science. 2008 Nov;327(2):308-15. <DOI>.

56. Nollet $H$, Roels $M$, Lutgen $P$, Van der Meeren $P$, Verstraete $W$. Removal of PCBs from wastewater using fly ash. Chemosphere. 2003 Nov;53(6):655-65. <DOI>.

57. Fan S, Wang $Y$, Wang Z, Tang J, Tang J, Li X. Removal of methylene blue from aqueous solution by sewage sludge-derived biochar: Adsorption kinetics, equilibrium, thermodynamics and mechanism. Journal of Environmental Chemical Engineering. 2017 Feb;5(1):601-11. $\leq$ DOI $>$.

58. Mouni L, Belkhiri L, Bollinger J-C, Bouzaza A, Assadi A, Tirri A, et al. Removal of Methylene Blue from aqueous solutions by adsorption on Kaolin: Kinetic and equilibrium studies. Applied Clay Science. 2018 Mar;153:38-45. $\leq \mathrm{DOI}>$.

59. Han $R$, Zhang J, Han $P$, Wang $Y$, Zhao Z, Tang $M$. Study of equilibrium, kinetic and thermodynamic parameters about methylene blue adsorption onto natural zeolite. Chemical Engineering Journal. 2009 Jan;145(3):496-504. <DOI>. 
